ON A CONTINUOUS EXPANSION STEAM ENGINE.

The object of this invention, as applied to Locomotive Engines, (as explained in detail in the former paper, see Proceedings, 
January, 1852,) is to obtain a greater amount of work from the same expenditure of steam or fuel than could be obtained from the present locomotive engines. It was pointed out that the extent to which the expansion of the steam could be carried was limited in the present locomotives, by the necessity of maintaining a certain amount of pressure in the steam at the moment of discharging it into the atmosphere, for the purpose of producing an efficient blast to maintain the intensity of the fire. If it were not for this circumstance, which prevented the expansion of the steam being carried in the cylinders beyond about 30lbs. per inch above the atmosphere, the expansion might be continued nearly down to the atmosphere, and most of the $30 \mathrm{lbs}$. so lost would be then made available as additional power obtained from the same steam. But the author of the paper had found, from experiments, that in the ordinary working, a portion of the discharged steam, probably as much as one-half, could be spared from the blast, provided the remainder was dis. charged at the full pressure of 30lbs., and he therefore retained that portion of the steam in his engine, and caused it to expand nearly down to the atmospheric pressure before it was discharged. This was accomplished by admitting the steam from the boiler only to one of the cylinders of the locomotive, where it was cut off at about half stroke, at which point the second cylinder was just commencing its stroke, (the two cranks being at right angles, as usual,) and a communication was then opened by the slide valve with the second cylinder, which was made from two to three times the area of the first cylinder. The steam was then expanded in both cylinders simultaneously, until the communication between them was closed, and the steam in the first cylinder was discharged as the blast, whilst that in the second cylinder, which had still half its stroke to perform, was further expanded down to the lowest point of efficiency. By this means, it was shown, a saving in consumption of steam and fuel of 20 per cent. would be effected, compared with the most economical working that could be maintained practically in the present engines, to perform the same work; whilst it would require 120 per cent. more fuel to do the same work with an engine that did not work expansively, and only cut off the steam at one inch from the end of the stroke, as many locomotives were formerly 
made. By the second oylinder being enlarged in area in proportion to the difference of average pressure, each cylinder exerted the same total moving power upon its crank, as in the ordinary engines, so that no practical difficulty was experienced; and the steam from the boiler could be admitted direet to the second cylinder by a stop valve for a short time, when required, to give an increased power at starting, or ascending inclines. Two practical trials had been made, which showed that the engines were not deficient in steam from the alteration of the blast, although working the regular passenger and goods trains at full speed. There had not been yet an opportunity for making sufficiently complete experiments to prove the relative economy, but the consumption of fuel was found to contrast favourably with the ordinary engines.

An accurate comparison of the relative amount of duty obtained from the same quantity of steam when employed in these different engines, is shown by the approximate Indicator diagrams, Figs. 1, 2, and 3, Plate 54. which bave been carefully drawn out from comparison with actual indicator diagrams, taken from locomotives, so as to allow correctly for the pressure of the exhaust and compression, and the wiredrawing of the valve.

Fig. 2 shows the performance of the steam in an Ordinary Engine, with two 15-inch cylinders $=353.4$ square inches area, and 24-inch stroke, cutting off the steam at 8 inches, or' $\frac{1}{3}$ rd of the stroke, at A. The pressure of the steam is $100 \mathrm{lbs}$. per inch above the atmosphere, but reduced by wiredrawing to $92 \mathrm{lbs}$. at the point of cutting off, so that the dotted line A $B$ represents the actual quantity of steam supplied to the two cylinders for one stroke, being $353.4 \times 8$ inches $=2827$ cub. in. at $92 \mathrm{lbs}$. per inch.

In this cese, and in the other two diagrams, the compression $\mathrm{C}$ has been made exactly sufficient to fill up the ports and clearance entirely to the full pressure of $92 \mathrm{lbs}$. steam, for the purpose of simplifying the comparison without interfering with the correctness of the result, so that the steam consumed in each case is exactly equal to the extent of motion of the piston to the point of cutting off the steam.

The steam is exhausted at $\mathrm{D}$, having been expanded down to $28 \mathrm{lbs}$. above the atmosphere, at which pressure it is discharged as the blast. 
The baok pressure $E$ is taken at 5lbs. pey inch at full speed-say forty miles per hour, from the end of the exhaust to the beginning of com. pression.

The average positive pressure throughout the stroke $=63.3 \mathrm{lbs}$.

$$
\begin{aligned}
& \text { " " negative " } \quad \text { " } \quad 10.1 \mathrm{lbs} \text {. } \\
& \text { Total effective pressure ... } 53 \cdot 2 \mathrm{lbs} \text {. }
\end{aligned}
$$

Total Power $=353.4$ in. area $\times 53.2$ lbs. per inch $=18,801$

Fig. 1 shows the performance of the same steam (2827 cub. in. at 92lbs. per in.) in the Continuous Expansion Engine; the first cylinder is $147.8 \mathrm{sq}$. in. area, (or about $13 \frac{3}{4}$ in. diameter,) and the second cylinder is three times the area $=\mathbf{4 4 3 \cdot 4}$ sq. in. area (or about 233 in. diameter,) both being 24-inch stroke, the same as before. The steam is cut off at $A$, at $16 \frac{1}{2}$ inches, or about $\frac{2}{3} r d s$ of the stroke of the small cylinder, and at $D$ at 1 inch of the stroke of the large cylinder. The dotted lines $\mathrm{AB}$ and $\mathrm{D}$, added together, represent the total quantity of steam admitted in each stroke, being equal to the line $\mathrm{AB}$ in Fig. 2.

The steam is expanded in both cylinders down to $30 \mathrm{lbs}$. per inch at the points $\mathrm{E}$ and $\mathrm{F}, 2$ inches from the middle of the stroke of the large cylinder, when the communication is shut between the two cylinders, and the steam in the first cylinder is discharged as the blast, amounting to 44 per cent of the whole quantity of steam admitted, and at the pressure of 30lbs.; being a little higher than the pressure of the blast taken in the ordinary engine, Fig. 2 , and about half the quantity of steam.

The back pressure $G$ in the small cylinder is taken at slbs. per inch, the same as in Fig. 2 ; but the steam in the second cylinder is further expanded down to 7lbs. per inch above the atmosphere before it is exhausted at $H$, and reduced nearly to the atmospheric pressure at the end of the stroke, the back pressure I being taken at $\frac{1}{2}$ lb. per inch. 
The average positive pressure throughont the stroke . . . . . . . . $=87.2 \mathrm{lbs} .30 .8 \mathrm{lbs}$. Ditto negative ditto ditto $=13.8 \mathrm{lbs}$. $4.9 \mathrm{lbs}$. Total effective pressure . . 73:4lbs. $25 \cdot 91 \mathrm{lbs}$.

Total Power, 1st cylinder, $147 \cdot 8$ in. ares $\times 73 \cdot 4$ lbs. per inch . . . = 10,849 2nd cylinder, 443.4 in. area $\times 25.91$ bs. per inch . . . = $=11,484$

$$
\begin{gathered}
\text { Total } . . \overline{22,393} \\
\text { Then 18,801:22,333 : : } 100: 119
\end{gathered}
$$$$
\text { Therefore Gain }=19 \text { per cent. }
$$

Consequently the power obtained in the Continuous Bpansion Engine, or the total shaded area of the Indicator diagrams; Fig. 1, is 19 per cont. greater than the power obtained from the same steam when employed in the Ordinary Engine, or the shaded area of the diagram Fig. 2, when the expansion is carried as far as appents to be found praoticable, consistently with the maintenance of a sufffdient pressure of blast.

Fig. 3 shows the power obtained from the rame quantity of steam in a Non-Expansive Engine when the steam is not cut off until 1 inch from the end of the 24 inch strolke; the cylinder is. then about $122.9 \mathrm{sq}$. in. area (or about 12 tumches diameter), containing the same quantity of steam (2327 cub. in., at 92albs. per in.) in 23 inches of the stroke, where it is cut off at $\mathrm{A}$, the dotted line $\mathrm{AB}$ being the same length as in the previous diagrams.

The back pressure $G$ is taken at the same, 5lbs. per inch, as in the first case.

The average positive pressure throughout the stroke $=97.0 \mathrm{lbs}$. Ditto negative ditto ditto $=14 \cdot 4 \mathrm{lbs}$.

$$
\text { Total effective pressure . . } \overline{82 \cdot 61 \mathrm{bs}} \text {. }
$$

Total Power $=122.9$ in, area $\times 82.91 \mathrm{bs}$ per inch $.=10,151$ 
Then 10,151:22,333:100:220

Therefore Gain $=120$ per cent.

of the Continuous Expansion Engine compared to a Non-Expansive Engine.

In the Continuous Expansion Engine, although the second cylinder is three times the contents of the first cylinder, the average pressure is about one-third, being $25.9 \mathrm{lbs}$. compared to $73.4 \mathrm{lbs}$, , so that the total propelling power of each of the cylinders is very nearly equal, as in an ordinary engine, and no practical objection is occasioned.

The application of the principle to Stationary Engines was described in the former paper, and it was shown to be a means of carrying the expansive principle to a greater extent than is practicable in the present engines, thereby proving an important source of economy, because of the great uniformity in the combined moving power of the two cylinders as exerted upon the crank shaft in a rotary direction, on account of the cranks being at right angles, and the continuous expansion of the steam in the two cylinders; but in ordinary engines the expansion could not be carried so far, where uniformity of motion was requisite, as in driving machinery, because of the great irregularity in the rotary power that was produced when the expansion was carried far.

The comparative effects were shown by a series of diagrams, of the variations in the total amount of moving power, or labouring force, exerted in the direction of the rotary motion of the crank, in the Continuous Expansion Engine, in Woolf's Double-Cylinder Engine, and in the Cornish Engine, taking the steam in each case to be admitted at 50lbs. per inch above the atmosphere, and expanded down to the lowest useful pressure before it is condensed. The following comparative results were obtained :-

\begin{tabular}{|c|c|c|c|c|}
\hline & $\begin{array}{l}\text { Continuous } \\
\text { Expansion } \\
\text { Engine. }\end{array}$ & $\begin{array}{l}\text { Woolf's } \\
\text { Engine. }\end{array}$ & & \\
\hline $\left.\begin{array}{c}\text { erage amount of irregularity in moving } \\
\text { power, throughout each stroke } \ldots\end{array}\right\}$ & $100-$ & 114 & - & 130 \\
\hline Extreme irregularity d & $100-$ & 135 & - & 284 \\
\hline the same steam or tuel & $100-$ & 109 & - & 111 \\
\hline
\end{tabular}


The general results of these comparisons being, that the Cornish Engine is 11 per cent., and Woolf's Engine is 9 per vent. more economical in expenditure of fuel than the Continuous Expansion Engine, when the expansion of the steam is carried to the extreme limit in each case; but that this economy cannot be obtained practically in those two engines, on account of the great irregularity in their moving power,-the average irregularity being in the Cornish Engine 30 per cent., and in Woolf's Engine 14 per cent. greater than in the Continuous Expansion Engine; and the extreme irregularity being 134 and 35 per cent. respectively greater.

Consequently it appears that, although the expansion of the steam cannot be theoretically carried to so great an extent in the Continuous Expansion Engine as in the other two engines;-yet from the moving power being so much more uniform throughout the stroke, the expansion can be carried practically to a considerably greater extent; and a greater amount of economy may be practically obtained within the same limit of uniformity in the moving power.

The comparison between the Continuous Expansion Engine and an ordinary Non-Expansive Condensing Engine, in which the steam exerts a uniform pressure upon the piston, from the commencement to the end of the stroke, shows that the variation in the development of moving power throughout one revolution, is in the former case only 43 per cent., and in the latter, 62 per cent., extreme variation from the average power.

The relative economy of the two Engines, or the amount of duty obtained from the expenditure of the same quantity of fuel in each case is as 100 to 38 ; so that the Continuous Expansion Engine does the same work as the Non-Expansive Engine, with a more uniform moving power, and with 62 per cent. less fuel.

The Chairman observed, that the subject of the paper was interesting and important, and it was well deserving of a thorough 
investigation. He enquired whether any indicator cards had been taken from the engines that were altered, to show the actual results?

Mr. SAMUEL replied, that the trials made were incomplete, and he had not had an opportunity of taking indicator diagrams from the engines, nor of carrying out the trials sufficiently to obtain comprehensive results suitable for laying before the Institution. One of the engines tried was a Goods Engine of the largest size, on the Eastern Counties Railway; the valves only were altered, and the second cylinder was not enlarged. It was only a temporary experiment, which of course caused a reduction in the extreme power that the engine could exert, and the object was more particularly to see how the principle could be best carried out in practice, and whether the proposed reduction in the blast could be effected; the result was a saving of 12 lbs. of coke per mile in consumption.

The Chairman remarked, that the steam was only supplied to one cylinder instead of two, and therefore so much less consumption of steam would take place.

Mr. SAmuec explained, that the engine did the same usual work during the trial as before; the engine-driver could work the engine in the ordinary manner up the inclines, by shutting the communication between the two cylinders, or the engine could not probably have taken the load through the trip, but he might be using more steam than usual in the one cylinder by keeping the regulator more open.

Mr. E. Jones thought the proposed plan deserved having eareful experiments tried: the diagrams shown were theoretical, and might mislead in the practical results, and he could not say how far they would agree with actual indicator diagrams, and he hoped a full trial would be made of the engine.

The Chairman considered it very desirable that the principle should be fairly tried; it seemed a good idea, and well worth being thoroughly worked out.

Mr. McConnell observed, that he had doubts whether an 
engine at considerable speed, using much steam, would get a sufficient blast if altered in the proposed manner, and would not require the blast-pipe to be reduced, involving a loss of power from that cause.

Mr. SAMUEL replied, that in the two engines that had been tried no difficulty appeared in making steam, and they were not found short of steam. Goods engines working at slow speed might perhaps be found the most useful cases for applying the principle. The other engine that had been tried was a passenger engine, in which the second cylinder was made double the area of the first; and it was never found short of steam, though running an express train of considerable weight. The results of the experiments as to economy were interfered with by a defect in the construction of the valves, which were tried with india-rubber packing at the back, as equilibrium valves, and proved leaky in working; and there was not an opportunity of carrying out the experiment further with valves of the ordinary kind, so that no sufficient results were obtained as to consumption, though as long as the valves remained in order the engine contrasted favourably in consumption with other engines of the same class and work. The only definite result obtained was with respect to the sufficiency of the blast, which proved quite satisfactory during the regular passenger train work of about a month.

Mr. McConnelu thought there would be an advantage in the relative consumption of fuel, from the engine employing less steam with the same boiler, as he considered it was an important source of economy of fuel to increase the heating surface in proportion to the consumption of the cylinders, particularly in the large goods engines.

The Chalrman observed, there was some uncertainty from the form of the experiment whether the economy observed was due to an improved mode of employing the steam, or was caused by not over-working the boiler; if less work was performed by the engine, then less steam was wanted from the boiler in the 
same time, and the smaller quantity of steam would be generated more economically from the same firegrate and heating surface.

Mr. McCoNNELL remarked, that great care would be required in setting the valves, to insure the proper action of the steam in the two cylinders; and it would be more important than in the case of the ordinary slide-valves, for the valve-gearing to be kept in perfect adjustment.

Mr.D.K. ClaRK (of Edinburgh) observed, in reference to the correctness of the conclusions to be drawn from the artificial indicator diagrams that were exhibited, that although they were artificial, they were founded on actual diagrams taken from locomotive engines, and therefore legitimate conclusions could be derived from them, and he considered they might be relied upon. The back pressure in the second cylinder, where there was no blast, had been taken in the diagram at only half-pound per inch, and would, of course, require to be matter of experiment to prove it positively; but he had observed the back pressure as low in locomotives where the valves and ports were properly adjusted; and in the diagram, taken from the Great Britain engine, at fifty-five miles per hour (which was before the Meeting), the back pressure was less than half-pound, with a blast pipe, when the steam was cut off at one-third of the stroke.

It had been assumed in the paper, that the steam could not be cut off in practice at less than one-third of the stroke, on account of the blast, but he had found it cut off at only one-fifth of the stroke in engines on the Caledonian Railway, and even less : still they worked well and appeared to make steam enough ; but then it was certainly down the heavy inclines where the consumption of steam was small.

The Chairman said there was one novel circumstance in the arrangement of the proposed engine, which did not appear correct in theory: in all the previous double-cylinder engines, the first piston was allowed to complete its stroke before the steam was expanded into the second cylinder, but in this engine 
the steam is passed into the second cylinder at the middle of the stroke of the first piston, thereby taking the steam away at the very moment that it is most efficient in the small cylinder.

Mr. SAMUEL explained, that at the half stroke of the first piston, the second piston was at its dead point, and began to move very slowly when the communication was opened between the two cylinders, and consequently took very little steam whilst the first piston moved through the greater portion of its remaining stroke; but then, as the first piston was getting less effective and approached its dead point, the second piston came gradually into full action, making a continuous expansive action, which was the peculiar feature of this engine, instead of the intermittent expansion of the other double-cylinder engines. This was borne out by the diagram, (Fig. 1,) showing a nearly continuous line of expansion ( $\mathrm{D} \mathrm{F} \mathrm{H}$ ) from beginning to end of the stroke; and the great uniformity in the total moving power of the two cylinders was shown in the former diagram, (Plate 53.)

Mr. SLAte wished some complete experiments should be made on the practical effect of expansion; he was doubtful whether so much of the theoretical advantage could be obtained in practice as had been supposed. In the present engine he could not understand the advantage of employing part of the steam at a lower pressure in a larger cylinder, as he thought that would cause the constant resistance of the atmosphere to be more seriously felt. If the strain were employed at the full pressure, say 90lbs., in the small cylinder alone, the atmospheric resistance would only cause a deduction of one-seventh of the whole power; but if the strain were only at about 30lbs. pressure in the large cylinder, this deduction for the atmospheric resistance would be increased to one-third of the power. Therefore it appeared to him most advantageous to employ the steam only in the small cylinder, to diminish the proportion of atmospheric resistance as much as possible. He thought the diagrams given, though borne out by the results of calculation, could not 
be argued from like actual indicator diagrams taken from the engine, and it was very desirable for those to be obtained.

Mr. SAMUEL said he had given the best information that he was able to furnish at present respecting the engine, and wished he could have supplied more practical results. He fully agreed on the importance of a thorough practical trial, and hoped that he had brought the importance of the subject sufficiently before the members to induce such of them as had the opportunity to give it a complete trial.

The Chairman remarked, that the pressure of the steam during expansion would be affected by the condensation that always took place to a considerable extent in the cylinder, and the expansion curve in the theoretical diagrams would consequently require practical correction for the condensation and temperature. There appeared to be always some condensation produced when steam was expanded.

Mr. CowPER thought the expansion curve could be practically laid down from Pambour's experiments, as the actual deviation in practice from the theoretical rate of expansion was very little. He thought there would not be found to be any loss by condensation in a well-protected cylinder; he had not found any condensation to take place in the experiments that he had tried on expansion.

The Chairman said he had always found a condensation take place in expanding steam, and he considered that the heat in steam was not sufficient to maintain all the steam in a gaseous state during expansion; and a portion of it was consequently condensed.

A vote of thanks was then passed to Mr. Samuel for his communication. 
NEW MODE OF MEASURING HIGH TEMPERATURES.

The following paper, by Mr. John Wilson, of Bridgewater Works, St. Helens, was then read:- 
Fig. 3. Thempometer:

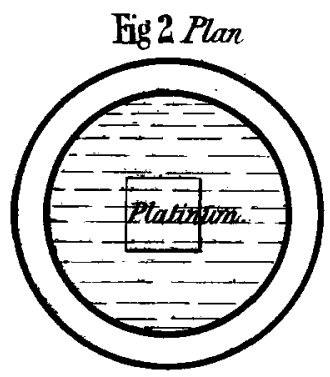

Scale $\frac{1}{2}$ size.
Fig. 4

\begin{tabular}{|c|}
\hline Platinum. \\
Icoo \\
grains.
\end{tabular}

Fig. 5 .

Stourbridge Clay. 200 grouins.

\section{EXPANSION OF STEAM.}

Fig. 1 Indicator Diagrams with very slow motion. from Caledonian Loconwtive NPI3.

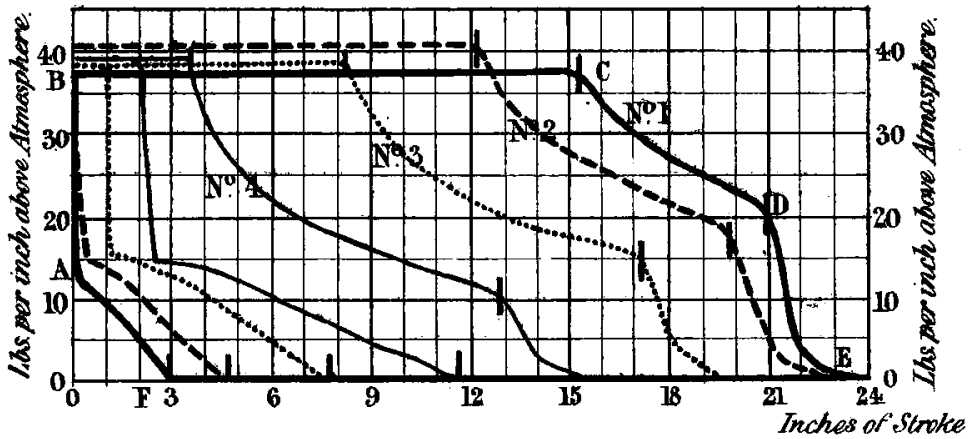

Fig. 6. Diagram of the actual consumption of Steam Per Horse power per hour.

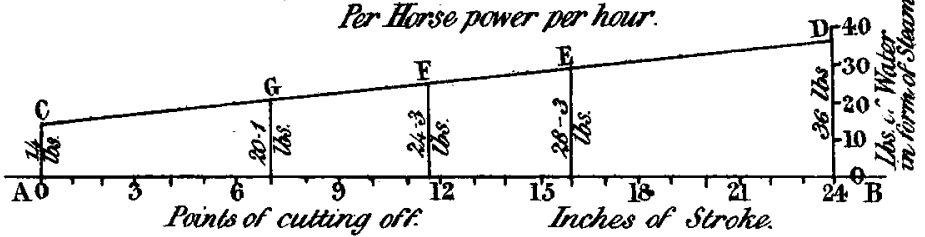

Fig. 7. Diagram of Maan Effective Pressure in Gilinder

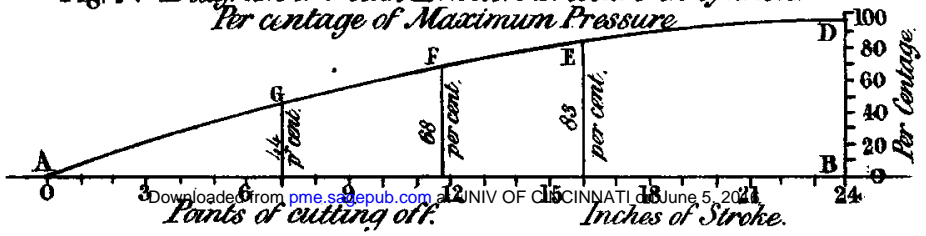

